\title{
Glocalization in Intercultural Crisis Communication: Lessons From D\&G's Incident in China
}

\author{
Xiaoya $\mathrm{Wu}$ \\ School of English for International Business, Guangdong University of Foreign Studies \\ Guangzhou, China
}

Huan Peng

School of English for International Business, Guangdong University of Foreign Studies Guangzhou, China

Weichao Wang (Corresponding author)

School of English for International Business, Guangdong University of Foreign Studies Guangzhou, China

E-mail: jasonwangw@gdufs.edu.cn

Received: April 5, 2021

doi:10.5296/ijl.v13i2.18575
Accepted: April 23, 2021

Published: April 29, 2021

URL: https://doi.org/10.5296/ijl.v13i2.18575

\begin{abstract}
In intercultural crisis communication, the globally adopted framework SCCT (Situated Crisis Communication Theory) should be adapted to meet the local contexts. By collecting online posts concerning D\&G's crisis communication from major Chinese social platforms including Sina Weibo, Zhihu (408 posts), WeChat official account (23 posts) as well as Instagram, Facebook and YouTube (344 posts), and with 10 semi-structured interviews (3 university professors and 8 students of different majors) for triangulation, this study analyzes the online posts concerning D\&G's crisis response strategies in China. We find that the public regard denial strategy as being outdated, demonstrating superiority and lack of responsibility; victimage strategy reflecting arrogance and self-centered mindset; moreover, the apologies are analyzed in terms of the manner and content of apology. Effective
\end{abstract}


intercultural communication presupposes equality, mutual respect and empathy; therefore, it is necessary to uphold a glocalization approach to crisis communication.

Keywords: Intercultural communication, SCCT, Crisis communication, Conflict resolution, Glocalization, Empathy

\section{Introduction}

Crises involving multinational enterprises in global contexts have been occurring regularly (Dhanesh and Sriramesh, 2018), and the specific problems that can arise have been amply demonstrated in the case of McDonald's company in Japan in 2014 where its decisive and quick responses to food safety violation turned out to be disastrous and the case of D\&G in China in 2018 where the company's promotional video and responses led to a loss of more than RMB 8 million Yuan.

The success of crisis communication depends on what an organization says and does immediately after a crisis occurs (Benoit 1997). Crisis communication framework has been provided to cope with crisis such as the Situational Crisis Communication Theory (SCCT). However, study of crisis communication in intercultural environments is needed to enhance this framework to deal with the problems that may arise in intercultural communication (Huang 2016).

Recently, various studies have attempted to analyze intercultural communication by case study (Dhanesh and Sriramesh 2018), experimental study (Laufer, Garrett and Ning 2018), or comparative analysis (Lyu 2012) whether crisis management differs in non-western countries such as China, Japan and India when compared with the West. The foci have been on how different contextual aspects such as culture, political systems, and media can influence the effectiveness of crisis communication strategies. In many of these studies, Hofstede's cultural dimensions (1991) have been used as the theoretical framework to explain the role of culture in selecting crisis communication strategies (Zhou and Shin 2017). The ways that the level of power distance can affect future purchase intentions when the CEO was the spokesperson during the crisis (Laufer and Garrett and Ning 2018) has been studied. Studies of traditional Chinese cultural values such as its collectivistic culture, nationalism, rationalism, and face-giving/saving have suggested that these should be taken into account in Chinese crisis communication (Huang et al 2016). Furthermore, the influence of differing political and legal systems, the level of economic development, media systems and activism has been highlighted in explaining the India's Nestle and Maggie noodle case (Dhanesha 2018) and online crisis communication in Chinese society (Cheng and Lee 2018).

Some studies contributed to stakeholders' perceptions and responses in specific connection to corporations' crisis communication responses. Lyu (2012) in comparing Taiwan and Mainland China's societies has examined newspapers' attitudes towards San Lu's crisis. Analysis of media coverage was used to explore the underlying political and media system reasons that led to the differences. Lyu (2012) also mentioned that different media systems might bring about different media performances. Ngai and Jin (2016) have divided public responses into different emotions such as anger, alert, worry, surprise, belief, sympathy, etc. 


\section{Mll Macrothink}

International Journal of Linguistics

ISSN 1948-5425

2021, Vol. 13, No. 2

The authors examined 8,530 responses from Chinese stakeholders to crisis communication on the Chinese Sina Weibo to enhance understanding of socially mediated crisis communication, the limitation of this study is the analysis of a solitary type of media content (i.e., Sina Weibo posts). Additional analyses of traditional news media content could provide a more in-depth study. They failed to do a content analysis of public perceptions from different platforms to clearly demonstrate the public attitudes. Compared with experiment analysis, content analysis can realize a deeper, more accurate and more comprehensive understanding of the public responses. Analysis of the content of public responses can demonstrate different cultural perspectives. Therefore, additional analyses of comments from different platforms of different stakeholders can provide a more in-depth and comprehensive study.

Investigation into crisis communication in the Chinese context is still a nascent endeavor. Studies in this field in China focus on two important issues: the contextual factors that affect the crisis communication and distinct crisis management strategies deployed (Wang and Laufer 2019). Ngai and Jin (2016) investigated the Chinese public's perceptions in Weibo (a Chinese social platform) to the crisis communication strategy employed after the crash of Asiana Airlines Flight 214. $\mathrm{Hu}$ and Pang (2018) explored indigenous corporate response strategies in the context of China's crisis response strategies. However, methodologically, these studies ignore content analysis of attitudes from different stakeholders. The rise of publicly available media online makes possible more transparent claims about stakeholder perspectives (Jiang; Huang; Wu; Choy; Lin, 2015).

Glocalization tries to seek a simultaneous attending to both global and local requirements (Lehmberg and Hicks 2018). In intercultural crisis communication, glocalization helps to adapt globally adopted frameworks according to local interpretations. This paper proposes a glocalization approach for the analysis of international crisis communication, via a case analysis of Dolce \& Gabbana (D\&G)'s unsuccessful crisis communication response strategy in China in 2018. More specifically, we ask: (1) What are the crisis communication strategies adopted by D\&G according to SCCT framework, and (2) what are the local interpretations of the globally adopted framework in the Chinese context? This study contributes to intercultural crisis communication literature in that the stakeholders' perspectives and a glocalization approach are employed to adapt the globally accepted crisis communication framework to this specific Chinese context by investigating the perspectives of the public.

\section{Literature Review}

\subsection{Crisis Communication}

A crisis is defined as the perception of an unpredictable event that threatens important expectancies of stakeholders and can seriously affect an organization's performance and generate negative outcomes (Coombs 2007). If a crisis is not properly dealt with in a short time, it will often bring harm to the image of the organization. Therefore, research about crisis communication, which refers to the way organizations use verbal and non-verbal responses to solve crises, have grown rapidly in the last two decades (Huang et al 2005). 
Situational crisis communication theory (SCCT) has been put forward as the theoretical approach adopted here. The SCCT framework is widely discussed in the field of crisis communication (Cheng and Lee 2018). SCCT demands a theoretical link between crisis situations and crisis response strategies (Coombs 2007). When an organization is involved in a victim crisis situation, it can adopt a denial strategy that emphasizes a defensive strategy. When an organization is involved in an unexpected crisis situation with medium responsibility, it can adopt eliminating strategies such as excuses and justification. When an organization is involved in a crisis situation with high responsibility for the misconduct, it should ideally take responsibility and adopt accommodative strategies such as the sincere apology (Tang and Lai 2017).

Based on the situational crisis communication theory, Tang and Lai (2016) chose the case of "cancer teacher dismissal" as the research object and used the content analysis method to analyze the response timing and communication strategies to identify the reason why Bowen College failed to respond to the online public opinion. It is concluded that the organization needs to analyze the type of public opinion crisis, the appropriate response strategies and also the relationship between the response strategy and the response time. However, Wu (2013) found the inconsistency between the practices and the theoretical suggestions in Taiwan's crisis communication and national contexts can account for the inconsistency. Hui Zhao (2020) examined the influences of national contexts on crisis attribution in SCCT, namely technological, political and cultural factors. In summary, organizations should pay more attention to the influences of national contexts on crisis attribution in SCCT.

Over the past two decades, many scholars have conducted theoretical verifications in different crisis cases (Wu 2013). Recent studies have found that not only the strategies used in non-western society are not entirely consistent with the theoretical suggestions in western society (Wu 2013) but also stakeholders in different countries react differently to a crisis and to crisis response strategies (Coombs and Laufer 2018). More researchers paid attention to integrating contextual factors including culture, political, media systems and many other factors (Lyu, 2012; Dhanesh and Sriramesh 2018) with theoretical framework in crisis communication. Dhanesh and Sriramesh (2018) held that crisis responses should take into account the influence of political and legal systems, the level of economic development, media systems, and activism.

More extant research emphasized the public responses in crisis communication. For example, Zhou and Shin (2017) used content analysis to examine press releases, news stories, and public comments related to crisis cases to test the effectiveness of stealing thunder in different environments. Ngai and Jin (2016) collected 8,530 responses from Chinese stakeholders to crisis communication on the Chinese microblogging Website Sina Weibo. Quantitative content analysis was used to analyze online public perceptions to the corporate responses of self-mockery by China's largest e-commerce company-Alibaba (Kim et al 2016). However, these studies focus mainly on collecting comments solely from Weibo or newspapers and categorize these comments into different attitudes such as anger, blame, positive or negative. Different stakeholders' perspectives are largely ignored. 


\section{Macrothink}

International Journal of Linguistics

ISSN 1948-5425

2021, Vol. 13, No. 2

Therefore, in this study, to achieve a thorough and comprehensive understanding of public attitudes towards a crisis, we not only collect comments from Weibo, Zhihu, WeChat as well as Instagram, Facebook and YouTube, but also have in-depth semi-structured interviews. Opinions from different stakeholders can help better understand Chinese people's attitudes towards crisis communication and formulate better strategies for crisis communication in the Chinese context. More and more research focus on testing the effectiveness of crisis communication strategies or of more tailor-made strategies for specific context from the responses of the public to crisis response strategies. It is important to collect comments from different platforms and analyze the content of these comments towards each strategy by SCCT. Thus, an in-depth investigation of stakeholders' perspectives to crisis communication in a specific and non-western context becomes crucial for international communication and for a critical analysis of crisis communication framework. Therefore, it is imperative to use a triangulation method to achieve glocalized crisis communication in the Chinese context for multinational corporations to achieve better intercultural communication in China.

\subsection{Glocalization}

We propose that glocalization can serve the internationalizing of crisis communication. As an approach, "glocalization" seeks to balance the universal (broad range of cultures) of globalization and the particular (specific cultures) of localization in a way that caters to a broader range of audience. George Ritzer (2003) defined glocalization as "the interpenetration of the global and the local resulting in unique outcomes in different geographic areas." It tries to seek a synthesized approach to meet both global and local requirements (Lehmberg and Hicks 2018). There is an impressive list of fields of study to which glocalization has been applied. For multinational enterprises, the concept of "glocalization" can help enterprises adjust their products or services to meet the needs of consumers in foreign markets (Chang 2016) since popular products in one area of the world are often rejected by customers in other geographic areas (Rugman 2014). There are many researches on the glocalization strategies used by multinational companies which diversify the local factors that should be taken into account in international marketing. During the expansion of Disneyland in Asia, it integrated globalization in management with localization in human resources and marketing. It modified its marketing strategies according to

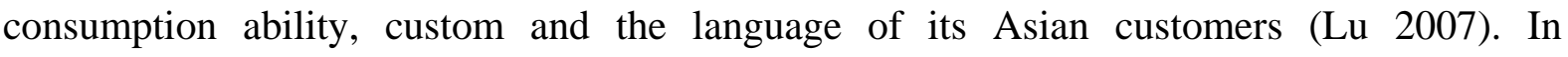
Bharti-Wal-Mart's glocalization experience, three categories of glocalization were listed including adaptation to Indian culture, adaptation to local brands and products and adaptation to local attitudes toward economizing (Matusitz 2015). Simi (2017) emphasized the importance of catering to local religious beliefs and philosophy in Subway's (a restaurant) expansion in India because 1/3 Indians are vegetarian. As to marketing expansion in China, Vogue magazine's Chinese version adopted a wide range of localization strategy, such as using the local model and story, using the Chinese characteristic mode of nonverbal communication, etc.

Likewise, one-size-fits-all crisis communication strategies that are effective in western societies may not be applicable in the Chinese society. Local factors essential to product and service marketing are also important in international crisis communication. The glocalization 
strategy is not only helpful in international marketing but also in intercultural crisis communication (Lehmberg and Hicks 2018). Within a given market or region, crisis communication could tailor globally adopted frameworks to local interpretations. In a case study involving McDonald's Corporation and its foreign subsidiary - McDonald's Japan, Hearit's (2006) three-part rhetorical model of apologia is adopted as a framework for crisis communication. Since the function and meaning of apology differ in Japan and the west, the manner and content of apology in Japan should be modified to meet local needs. Although glocalization can be applied to international crisis communication, it has only studied varying interpretations to an apology in the Japanese context. For example, the apology meeting was convened and run by two senior Japanese executives rather than the president of McDonald's Japan. It sent a message to customers and victims that the company does not take these incidents seriously and that they are not big enough for the president to explain publicly, or for its employees take it seriously. During the apology meeting, executives provided the detailed information of the incident. However, Japanese interpreted this as "to offer an excuse" (Lehmberg and Hicks 2018). There are many other strategies for crisis communication and local interpretations to them in different contexts have not been fully studied. Whether factors taken into account in international marketing should be given equal importance to glocalization of international crisis communication remains unclear. A comprehensive and objective investigation of different stakeholders' attitudes in one region could offer insights into the glocalization of crisis communication.

\subsection{The Role of Social Media in Crisis Communication}

With the rapid development of new media technology, social media has changed the way people communicate and analyze information. Through social media, individuals can exchange information with large groups of people in real time. Moreover, web-based mobile devices have made social media readily accessible. Since social media makes a two-way communication possible, it can be used in four types of crisis communication (Reuter et al., 2012): communication from organizations to citizens (A2C), communication between citizens $(\mathrm{C} 2 \mathrm{C})$, communication from citizens to organizations $(\mathrm{C} 2 \mathrm{~A})$ and communication between authorities (A2A). The present study focuses on A2C - Organizations use social networking sites to reach out to the public for crisis communication, $\mathrm{C} 2 \mathrm{C}$ - Citizens may collect information of the organization's crisis communication and spread it to other citizens and $\mathrm{C} 2 \mathrm{~A}$ - Citizens make comments on crisis communication response. Public-generated content is useful in gauging the sentiment and attitudes to crisis communication (Serrano et al, 2017).

\subsection{Context Analysis and Process Analysis}

Five-part framework is built to analyze complex negotiation including identification of negotiation architecture, context analysis, structural and relational analysis, process analysis and decisional analysis (Crump 2015). We mainly focus on context analysis and process analysis in this paper. Context analysis seeks to examine the specific context in which a complex negotiation occurs. Process analysis can identify the date and event of the negotiation, which can be further divided into phases or stages of negotiation process. This is 
an analytical tool for achieving understanding. In this paper, context analysis and process analysis are necessary to have a clear understanding of the case and achieve glocalization of crisis communication.

\section{Methods}

\subsection{Case Study Research}

This study examines the opinions from different stakeholders to reveal crisis communication in the Chinese context by analyzing D\&G's case. Case study is most appropriate to examining the role of contextual variables (Dhanesh and Sriramesh 2018), in that it can provide "an intensive, holistic description and analysis of a single entity, phenomenon, or social unit" (Merriam 1998: 34). Case study is well suited for developing an in-depth, contextual, and holistic understanding (Yin 2009). In this study, drawing on multiple sources of data, case study allows us to gain insights into public responses to a crisis. A review of recent case studies reveals that contextual factors could influence crisis communication. For example, Zhu (2017) provided important insights for practitioners and scholars to consider local contexts in crisis communication by a case study of McDonald's and KFC's crises management in China.

\subsection{Triangulation}

Triangulation is adopted as a method to collect public responses, and content analysis is used to examine and categorize crisis communication strategies and public responses. Triangulation means to combine multiple research materials, researchers, research theories and research methods to analyze the same problem in the same research to obtain a comprehensive in-depth explanation of the research problem, and to improve the breadth, depth and dimension of the analysis (Sun 2006). In this paper, triangulation method can help to obtain opinions to achieve glocalization of crisis communication in the Chinese context. We collected posts towards D\&G's crisis communication from major Chinese media platforms including Sina Weibo, Zhihu (A total of 408 posts), WeChat official account (23 posts) as well as Instagram, Facebook and YouTube (344 posts) to represent different stakeholders' perspectives.

Social media provides a new platform that sheds light on how the public reacts to crisis communications. Sina Weibo is "a Twitter-like microblogging service provided by Sina Corporation" (Yuan and Feng and Danowski 2013: 1014). Without the requirement of high level of knowledge and expression ability, its users cover a wide range of social strata (Wang and Liu 2017).

Zhihu's user basis is China's emerging middle class and influential people. The proportion of people with higher education in Zhihu reaches $80.1 \%$. The proportion of people with master's degree or above is higher than the overall level. Nearly $20 \%$ of users have overseas study experience (Chen and He 2019). Zhihu users mainly come from practitioners and scholars in science and technology, media, law, culture, art and other fields (Chen and He, 2019). They are active in the fields they are good at or interested in (Ru and $\mathrm{Hu} 2016)$. Based on their own 
professional knowledge, they can answer relevant questions professionally and objectively ( $\mathrm{Ru}$ and $\mathrm{Hu} 2016)$.

Additionally, we also collected 23 articles about D\&G's crisis communication from WeChat official accounts. WeChat's official account can provide a new way of information dissemination for media and individuals. In recent years, the scale of WeChat users continues to expand, becoming the communication tool with the highest frequency and longest duration (Yang, 2020). WeChat official account is based on WeChat's huge user base. It fits the current people's fragmented reading habits, and the transmission form is relatively new, attracting audiences through video, graphic and text combination, and effectively improving the effectiveness of information dissemination (Yang, 2020).

Facebook is a social network service in the United States and Instagram is a photo-sharing social application. YouTube is the largest video website in the world. On these platforms, we only analyze text messages but exclude content such as pictures, videos, and hyperlinks from analysis.

Semi-structured interviews help us have a better understanding of the responses. There are two types of interviews: face-to-face interviews and online interviews. Firstly, we are able to collect specific and accurate information, which online comments fail to provide. Secondly, interview can help us have a deeper and more comprehensive understanding of the comments collected. We conducted interviews with three university teachers and eight students of different majors. The three university teachers include one Australian teacher from Guangdong University of Foreign Studies and two teachers from Hefei Normal University. All the teachers are professors who teach Business English. $\mathrm{T}$ is a professor from University of Technology Sydney, who has been working at universities in Japan, the U.S. and Australia for over 30 years; $\mathrm{Yu}$ is an associate professor in the school of foreign languages of Hefei Normal University. She was a visiting scholar at New York University and San Diego State University. Her main research interests are intercultural communication and English language testing. Zheng is an associate professor with research interests in Business English, language, cultural soft power and international politics. Although these teachers are not experts in crisis communication, they are professional in cross-cultural research. The eight students include 5 boys and 3 girls at the average age of 24.7 students are graduate students among whom there are 1 medical major- Pan, 1 psychological major - Zheng, 1 political major - Han and 4 English Majors - Li, Hu, Xiong, Wang. There is 1 undergraduate student specializing in lawXiao.

Comments on platforms and from interview represent opinions of the nation, the whole public. The whole nation rather than only consumers should be the focus of our intercultural study because the research is conducted from the perspective of intercultural crisis communication. This is not research about product promotion, which requires collection of feedback from users. It is because they are naïve to crisis communication knowledge that their comments can reflect the common people's views, just as the members of the jury do not need systematic legal knowledge. 


\section{Review of the Case}

Table 1. Timeline of D\&G's incident in China

\begin{tabular}{|c|c|c|c|c|c|}
\hline Time & $\begin{array}{l}\text { November 17, } \\
2018\end{array}$ & $\begin{array}{l}11: 00 \quad \text { am, } \\
\text { November } \\
17,2018\end{array}$ & $\begin{array}{l}1: 52 \quad \mathrm{pm}, \\
\text { November } \\
21,2018\end{array}$ & $\begin{array}{l}4: 48 \quad \mathrm{pm} . \\
\text { November } \\
21,2018\end{array}$ & $\begin{array}{l}\text { November } \\
23,2018\end{array}$ \\
\hline Event & $\begin{array}{l}\text { The } \\
\text { promotional } \\
\text { video released }\end{array}$ & $\begin{array}{l}\text { Insulting } \\
\text { words } \\
\text { exposed } \\
\text { online }\end{array}$ & & $\begin{array}{l}\text { "The Great } \\
\text { Show" } \\
\text { canceled }\end{array}$ & \\
\hline Response & & & $\begin{array}{l}\text { "Being } \\
\text { hacked" } \\
\text { statement } \\
\text { released }\end{array}$ & $\begin{array}{l}\text { Victimage } \\
\text { response } \\
\text { released }\end{array}$ & $\begin{array}{l}\text { Apology } \\
\text { video } \\
\text { released }\end{array}$ \\
\hline
\end{tabular}

\subsection{Stage 1: D\&G's Video Release}

On November 17, 2018, Dolce \& Gabbanna (D\&G), a luxury brand in Italy, released a promotional video "Eating with Chopsticks" to warm up "The Great Show" in Shanghai, China. The video was released in D\&G's Weibo official account and D\&G's official account in Instagram. The video depicts a Chinese woman, bedazzled in D\&G's jewelry, using chopsticks to eat pizza, spaghetti, and an oversized pastry called cannoli. However, the video arouses controversy about racial discrimination. There are comments like "I feel bad for the model", "I found it absolutely offensive", and "Such tasteless ads. Full of sexual innuendos and condescending remarks", "The tone is insulting. The tone sounds so much like he pities her for being in China." "You are showing an overly dressed individual who look stupid trying to eat Italian food with 'small stick shaped cutlery'." There are also comments with neutral sentiment towards this video: "I don't get why it is racist. Could someone please explain in a friendly manner?" "I don't see any racism content in this ad. Can someone explain to me?".

\subsection{Stage 2: D\&G's Insulting Words Provoke Public Anger}

On November 21, 2018, at 11 am, the insulting words "country of shit" made by one of D\&G's designers was exposed online which immediately provoked public anger. An Asian model exposed a screenshot of her conversation with Stefano Gabbana, designer of D\&G on social media Instagram. In this screenshot, the designer used the poop emoji to attack China in this statement: "I will say the country of (the poop emoji) is China." Netizens' comments are more negative than the early advertisements with words such as "get out, insult, farewell and trash”. Many famous Chinese stars including Kun Chen, Ziyi Zhang, Junkai Wang and some models declared their non-attendance at D\&G's Shanghai show. They declared their stands in Weibo. Kun Chen says, "I will not attend D\&G's show tonight." Ziyi Zhang says, "Ziyi Zhang will not attend the D\&G show in Shanghai tonight. From now, Ms. Zhang and her team will not purchase or use any D\&G products." Junkai Wang: "it is no doubt that you are the best, my country." Bingbing Li: "I love my country." Chinese netizens also expressed 
their anger: "we can never forgive the words 'country of shit'. Please get out of China". "Get your shit cloths out of China."

\subsection{Stage 3: "Being Hacked"}

At 1:52 p.m., November 21, 2018, D\&G later posted a statement on Instagram and Weibo that one of D\&G designer's account (on which the insulting words "country of shit" was made) had been hacked but the statement aroused more criticism. Some netizens said, "This is an outdated excuse. I don't believe it." "It is too stupid for them to use this excuse." "They insult our intelligence. They insult us again. "At the same time, the communist youth league's official account released a statement in Weibo that "We welcome foreign enterprises to invest and do business in China, and foreign enterprises operating in China should respect China and the Chinese people. This is also the minimum requirement for any enterprise to invest in other countries and carry out cooperation."

\subsection{Stage 4: "The Great Show" Canceled}

D\&G's Shanghai show, scheduled for November 21, 2018, was canceled after many famous Chinese stars ceased to attend the show. D\&G prepared an enormous show covering 18700 square meters with 40 stars, 360 models, 1600 furnishings and equipment, 500 pieces of clothes, totaling 8 million RMB. Then, at 4: $48 \mathrm{pm}$, D\&G made a response on Instagram and Weibo that it is not only unfortunate to them, but to those work day and night for the show. In the evening, Chinese stars including Dilireba and Junkai Wang announced their termination of the agreement with D\&G. After models and stars issued boycott statements, eight mainstream e-commerce platforms operating luxury business in China have removed all products related to $\mathrm{D} \& \mathrm{G}$ off the shelves including three major e-commerce giants T-mall, Jingdong and Suning e-commerce as well as Netease koala, luxury e-commerce Siku, Vipshop, Store 1 and overseas shopping platforms.

\subsection{Stage 5: Apology Video Released}

On November 23, 2018, finally, three days after the promotional video was released, the two designers made an apology in a short video in Weibo. After 3 hours, they released it in Instagram, Facebook. However, the video caused a lot of controversy as well.

\section{Theoretical Framework}

SCCT proposes that an organization's reputation and image could be restored if it chooses an appropriate crisis communication response (Coombs 2006). The SCCT framework includes attacking the accuser, denial, scapegoating, making excuses, justifications, compensation, and apology strategies, etc. When a crisis occurs, an organization should first classify the crisis according to the initial crisis responsibility. SCCT proposes that a crisis response strategy should match the crisis situation (see Tables 2 and 3). In a victim cluster, for example a natural disaster, rumor, workplace violence and product tampering, the denial strategy should be adopted to the crisis such as denial or attacking the accuser because the organization is a victim of the crisis with no responsibility. In the accidental cluster such as a technical error or product accident, the diminishing strategy should be adopted such as excuse and justification 
because the organization has medium responsibility. In the preventable cluster such as human-error accident and organizational misdeed, the rebuild strategy should be adopted such as compensation and apology because the organization has to take full responsibility for the accident. The reputational threat is also affected by the other two factors including crisis history and prior relational reputation.

Table 2. Crisis clusters and corresponding degree of responsibility

\begin{tabular}{llll}
\hline Crisis clusters & Crisis types & Degree of responsibility \\
\hline Victim cluster & $\begin{array}{l}\text { Natural disaster/rumor/ } \\
\text { violence/ Product tempering }\end{array}$ & Workplace & No responsibility \\
& Challenges/ Technical-error & Medium responsibility \\
& accidents/Technical-error product harm & \\
\hline Preventable cluster & Human-error accidents/ & High responsibility \\
& Human-error product $\quad$ harm & \\
& /Organizational misdeed with no & \\
& injuries/ Organizational misdeeds & \\
& management & misconduct// & \\
& Organizational misdeed with injuries & \\
\hline
\end{tabular}

Table 3. The match between crisis cluster and response strategies

\begin{tabular}{lll}
\hline Crisis Cluster & Response Strategy & Specific Strategies \\
\hline Victim & Deny & Attack, Denial, Scapegoat \\
\hline Accidental & Diminish & Excuse, Justification \\
\hline Preventable & Rebuild & Compensation, Apology \\
\hline Bolstering & & Reminder, Ingratiation, Victimage \\
\hline
\end{tabular}

\section{Data Collection}

Qualitative content analysis is used to explore the response strategies of D\&G. Qualitative content analysis allows for the interpretation of content using systematic classification process of coding and identifying themes or patterns (Schreier 2012). The difference between quantitative and qualitative content analysis is that the former is a research technique used to examine manifest content of communication in terms of frequency counts (Berelson 1952), while the latter goes beyond frequency counts. Besides analyzing manifest content, it dives deeper and seeks to understand latent meanings (Kracauer 1952). The three main crisis communication strategies of "denial", "victimage", and "apology video" were adopted by $\mathrm{D} \& \mathrm{G}$ in an attempt to restore their image, according to SCCT (listed in Table 4). In the apology video, we coded three sub-strategies with an apology and the ingratiation strategies explicitly mentioned by Coombs. Public opinion towards D\&G can be deduced from the public comments posted in official social media accounts in Weibo, Zhihu, WeChat, Facebook, Instagram, and YouTube. In order to collect data in these different platforms, we have taken different measures. 
Firstly, on Weibo platform, D\&G posted the three responses on D\&G's official Weibo account. However, since D\&G opened the comment selection function for the denial response and victimage response, we have no access to check the comments on these two responses. Therefore, we have to collect comments on the first two responses from one of China's most influential Weibo account - Global Times. The reason why we collect comments from Global Times is listed as below. Wu Zhongyuan (2018) took the official microblogs of 15 traditional media as the research object. He selected six key indicators, and used SPSS software to conduct principal component analysis on the factors that determine the influence of traditional media microblogs. Finally, it is concluded that the top three most influential news media are People's Daily, CCTV News and Global Times. However, on the CCTV News platform, there is no discussion on D\&G's three responses. Finally, we found the post about denial strategy in the Global Times and the post about victimage in the People's Daily. Therefore, we collected comments on denial from the Global Times (Note 1) and on victimage from People's Daily (Note 2) and on apology from under D\&G's post in the official account (Note 3 ) in descending order of the number of likes.

Fortunately, the Instagram account of $D \& G$ is the main channel for them to spread information and release products. We found three responses from D\&G's posts in Instagram respectively, under which we selected 89 comments on the first response, 70 comments on the second response and 82 comments on the third response respectively in descending order of the number of likes.

However, on Zhihu, Facebook and YouTube, there are few topics separately related to the three crisis communication strategies by $D \& G$. Therefore, it is deemed necessary to isolate the attitudes related to the three crisis communication strategies from these comments. When coding public comments towards D\&G's crisis responses, coders firstly have to identify which crisis response each public comment is responding to, and ignore irrelevant comments.

We also collected 23 articles from WeChat official accounts by conducting a search of the keywords "D\&G's crisis communication". We have to check all the articles under these keywords one by one and eliminate repetitive articles. After collecting the final 23 articles, the last step is to isolate attitudes to the three strategies respectively.

Finally, in order to have a thorough investigation of public attitudes, 3 teachers in university and 8 students with different majors were interviewed. The detailed information of them is listed in the triangulation part. The number of comments from different channels are listed in Table 5.

Table 4. Crisis communication strategy adopted by D\&G

\begin{tabular}{lll}
\hline Media reports & Response & Response strategy \\
\hline $\begin{array}{l}\text { Insulting words } \\
\text { provoke public anger }\end{array}$ & Hacked, rumor & $\begin{array}{l}\text { Denial: attacking the accuser: } \\
\text { others setting me up }\end{array}$ \\
\hline $\begin{array}{l}\text { Stars cease attendance } \\
\text { at the show }\end{array}$ & $\begin{array}{l}\text {...not only unfortunate to us, but } \\
\text { to those worked day and night } \\
\text { for this. }\end{array}$ & \\
\hline
\end{tabular}




$\begin{array}{lll}\begin{array}{l}\text { Apology video } \\ \text { released }\end{array} & \text { is } \frac{\text { culture }}{\text { Claiming they love China and Ingratiation }} \\ & \text { Chinese culture. }\end{array}$

Table 5. Number of comments collected

\begin{tabular}{llll}
\hline & denial & victimage & apology \\
\hline Weibo & 95 & 97 & 103 \\
\hline Zhihu & 36 & 26 & 51 \\
\hline Facebook & 12 & 1 & 8 \\
\hline Instagram & 89 & 70 & 82 \\
\hline YouTube & 24 & 4 & 54 \\
\hline WeChat official accounts & 23 articles & & \\
\hline Interview & 11 interviewees including 3 teachers and 8 students
\end{tabular}

\section{Analysis}

As demonstrated in the above tables, the crisis communication, namely denial, victimage, apology adopted by $D \& G$ engender different public responses. In the analysis section, we will analyze and categorize responses towards each strategy to reveal attitudes in detail.

\subsection{Denial Strategy}

The denial response is adopted to deal with the crisis of the insulting statements made by one of the two designers. After categorization, comments towards this statement is listed in Table 6. This statement which was released in Instagram and Weibo (Note 4) is as follows:

"Our Instagram account has been hacked. So as the account of Stefano Gabbana. Our legal office is urgently investigating. We are very sorry for any distress caused by these unauthorized posts. We have nothing but respect for China and the people of China."

Table 6. Comments on denial strategy

\begin{tabular}{|c|c|c|c|c|c|c|c|}
\hline & Weibo & Zhihu & WeChat & Instagram & YouTube & Facebook & Interview \\
\hline \multirow{5}{*}{$\begin{array}{l}\text { Authoritative } \\
\text { confirmation }\end{array}$} & Please show & Facebook's & It is so stupid & Where is the & & & \\
\hline & official proof & security team & unless you can & investigation & & & \\
\hline & (暴躁汪) & can provide & produce a platform & results? & & & \\
\hline & & them with login & or police certificate & (Sylviali0731) & & & \\
\hline & & records (罗磊) & (万能的大叔) & & & & \\
\hline
\end{tabular}




\begin{tabular}{|c|c|c|c|c|c|c|c|}
\hline $\begin{array}{l}\text { Outdated } \\
\text { excuse and } \\
\text { arrogance }\end{array}$ & $\begin{array}{l}\text { I thought there } \\
\text { wasn't such } \\
\text { stupid PR } \\
\text { anymore. It is } \\
\text { so outdated } \\
\text { (Jee) }\end{array}$ & $\begin{array}{l}\mathrm{D} \& \mathrm{G} \text { is so } \\
\text { childish to shirk } \\
\text { responsibility } \\
\text { with such an } \\
\text { excuse (伊小甸) }\end{array}$ & $\begin{array}{l}\text { It is difficult for } \\
\text { D\&G to get away } \\
\text { with this with such } \\
\text { an childish excuse. } \\
\text { (章辞) }\end{array}$ & $\begin{array}{l}\text { The hackers not } \\
\text { hacked the ID, } \\
\text { they hacked the } \\
\text { designer's head. } \\
\text { (Sunnysunny } \\
619 \text { ) }\end{array}$ & $\begin{array}{l}\text { This is an } \\
\text { excuse. (Mike) }\end{array}$ & & $\begin{array}{l}\text { He is reluctant to } \\
\text { spend time and } \\
\text { efforts explaining } \\
\text { the insulting } \\
\text { words. So he } \\
\text { chooses a simple } \\
\text { and } \\
\text { response. } \\
\text { (Zheng) }\end{array}$ \\
\hline Prior history & & $\begin{array}{l}\text { I don't believe in } \\
\text { being hacked. } \\
\text { Because they } \\
\text { used to flirt with } \\
\text { Chinese culture. } \\
\text { (冷芸) }\end{array}$ & & & $\begin{array}{l}\text { I think we need } \\
\text { to look at the } \\
\text { previous } \\
\text { behaviors of } \\
\text { Gabbana. (Kat } \\
\text { and kim) }\end{array}$ & $\begin{array}{l}\mathrm{He} \text { is liar and } \\
\text { sexist and } \\
\text { racist homo! }\end{array}$ & $\begin{array}{l}\text { We can see they } \\
\text { disrespect } \\
\text { Chinese culture } \\
\text { from their } \\
\text { previous } \\
\text { promotional } \\
\text { photos. (Zheng) }\end{array}$ \\
\hline Value & & $\begin{array}{l}\text { Values are the } \\
\text { cornerstone of } \\
\text { an enterprise at } \\
\text { any time. (姐夫 } \\
\text { 李公关) }\end{array}$ & $\begin{array}{l}\text { It is necessary for } \\
\text { them to rebuild } \\
\text { their value. (网络 } \\
\text { 與情和危机公关) }\end{array}$ & & & & \\
\hline Sincerity & & $\begin{array}{l}\text { The core of } \\
\text { crisis public } \\
\text { relations is } \\
\text { sincerity and } \\
\text { responsibility. }\end{array}$ & $\begin{array}{l}\text { The golden rule of } \\
\text { crisis management } \\
\text { is sincerity and } \\
\text { speed. }\end{array}$ & $\begin{array}{l}\text { Your account } \\
\text { isn't hacked. If } \\
\text { you want to } \\
\text { apologize ! Do it } \\
\text { in a sincere } \\
\text { manner. } \\
\text { (Zoeexiao) }\end{array}$ & & & $\begin{array}{l}\text { They are } \\
\text { definitely } \\
\text { insincere. } \\
\text { (Xiong) }\end{array}$ \\
\hline Speed first & & & $\begin{array}{l}\text { When a crisis } \\
\text { occurs, companies } \\
\text { should respond } \\
\text { quickly and control } \\
\text { the situation. }\end{array}$ & $\begin{array}{l}\text { Your posts means } \\
\text { nothing. It's too } \\
\text { late. (Minicyn) }\end{array}$ & & & \\
\hline $\begin{array}{l}\text { Responsibilit } \\
\mathbf{y} \\
\text { and courage }\end{array}$ & & $\begin{array}{l}\text { People who } \\
\text { have the courage } \\
\text { to do bad thing } \\
\text { but lack the } \\
\text { courage to bear } \\
\text { the } \\
\text { responsibility } \\
\text { are the most } \\
\text { obscene. }\end{array}$ & $\begin{array}{l}\text { In the face of crisis, } \\
\text { enterprises must try } \\
\text { their best to } \\
\text { appease consumers, } \\
\text { compensate } \\
\text { consumers' } \\
\text { interests and have } \\
\text { the courage to take } \\
\text { responsibility. }\end{array}$ & $\begin{array}{l}\text { You two are } \\
\text { cowards. } \\
\text { (Cmba8) }\end{array}$ & & & $\begin{array}{l}\text { They are trying } \\
\text { to pass the buck. } \\
(\mathrm{Hu})\end{array}$ \\
\hline
\end{tabular}




\begin{tabular}{|c|c|c|c|c|c|}
\hline $\begin{array}{l}\text { Conflict of } \\
\text { civilization }\end{array}$ & $\begin{array}{l}\text { Information that is } \\
\text { humorous on "we } \\
\text { media" platform in } \\
\text { one culture will } \\
\text { produce } \\
\text { immeasurable } \\
\text { public opinion } \\
\text { responses in } \\
\text { another culture. }\end{array}$ & & & & \\
\hline $\begin{array}{l}\text { National } \\
\text { dignity }\end{array}$ & $\begin{array}{l}\text { There is a group of } \\
\text { post-90s network } \\
\text { nationalists. (新传 } \\
\text { 考研真经) }\end{array}$ & & & & $\begin{array}{l}\text { Insulting our } \\
\text { nation can never } \\
\text { be forgiven no } \\
\text { matter what } \\
\text { response D\&G } \\
\text { makes. (Xiao) }\end{array}$ \\
\hline $\begin{array}{l}\text { Vulgar } \\
\text { language }\end{array}$ & & $\begin{array}{l}\text { Shit brand, shit } \\
\text { design. } \\
\text { (Young_yuting) }\end{array}$ & & & \\
\hline $\begin{array}{l}\text { Swearing not } \\
\text { to buy } \\
\text { D\&G's } \\
\text { product }\end{array}$ & & $\begin{array}{l}\text { I will buy } \\
\text { nothing from } \\
\text { D\&G. } \\
\text { (S.september) }\end{array}$ & & & \\
\hline $\begin{array}{l}\text { No words for } \\
\text { promotional } \\
\text { video }\end{array}$ & & & & $\begin{array}{l}\text { Many of my } \\
\text { Chinese } \\
\text { friends think } \\
\text { these videos } \\
\text { are } \\
\text { stereotypical, } \\
\text { racist and } \\
\text { disrespectful. } \\
\text { However, No } \\
\text { apology was } \\
\text { made. (Jasmin } \\
\text { M. Zhang) }\end{array}$ & $\begin{array}{l}\text { Cause of this } \\
\text { incident is that } \\
\text { video but they } \\
\text { fail to explain it. } \\
\text { So they are } \\
\text { diffident about it } \\
\text { because they } \\
\text { truly } \\
\text { discriminate } \\
\text { against Chinese } \\
\text { people. (Pan) }\end{array}$ \\
\hline Overreaction & $\begin{array}{l}\text { The correct brand } \\
\text { awareness is to } \\
\text { keep pace with the } \\
\text { time because the } \\
\text { brand rather than } \\
\text { the product leaves } \\
\text { impression on } \\
\text { users. (Kuangzhen } \\
\text { MIC) }\end{array}$ & & $\begin{array}{l}\text { The quality of } \\
\text { clothes from this } \\
\text { brand is very } \\
\text { good actually, } \\
\text { not like other } \\
\text { brands, which } \\
\text { focus on quantity } \\
\text { rather than } \\
\text { quality. (Cris) }\end{array}$ & & \\
\hline
\end{tabular}


The responses were classified by social media platform. Combined with the above table, We would like to introduce the views on denial strategies collected from different platforms as a whole. Since users on different platforms have different educational backgrounds and social status, some comments overlap while others are different.

The comments on the denial strategy collected from the Weibo platform mainly focus on three aspects: authoritative confirmation and outdated, flimsy excuse.

The main findings from Zhihu platform include the prior history, enterprise values, attitude and sincerity of response, and responsibility and courage in addition to the above mentioned two aspects.

In WeChat official accounts, four new ideas are discovered, including speed first, responsibility, national sentiment, civilization conflict.

In the comments on Instagram platform, attitude, sincerity, courage and speed are also mentioned as well as insulting remarks and swearing that they would not buy their products in the future. Most of them were emotional and abusive.

On the YouTube platform, someone makes a rational analysis on the possibility of being hacked, proving that it was impossible to be hacked and mentioned D\&G's previous behavior. However, the most noteworthy thing was that a user in YouTube and a user in WeChat have conflicting opinion in the overreaction aspect.

On Facebook, it is mentioned that the denial response only explained the insulting remarks, but did not explain the previous promotional video, which was also mentioned in interview.

In the interview, professor Zheng thinks that the being hacked strategy reflects D\&G's arrogance. What's more, Xiao mentions national dignity, which coincides with the above-mentioned national sentiment in WeChat official account.

The different views will be analyzed in detail in the following part.

\subsubsection{Prior History}

According to SCCT, D\&G adopted the denial strategy to prove their innocence. SCCT states that if the organization wants to take no responsibility for the crisis, the denial strategy can be used for spreading rumors and challenging the crisis. D\&G regarded the crisis as being a result of being hacked by others. However, the reputational threat is also affected by the other two factors: crisis history and prior reputation. $D \& G$ has a history of similar crises and a prior negative relationship reputation. Leng Yun, a Zhihu user, said, "They are definitely not hacked because they have offended Chinese culture before." (Note 5) In an interview with professor Zheng (Dec. 23, 2019), he displayed the promotional photos made by D\&G in 2018, which also insulted Chinese people by an intentional sharp contrast between glamorous models and ragged Chinese people. Kat and kim, a YouTube also user said, "I think we need to look at the previous behaviors of Gabbana." The denial strategy backfired in this case. 


\subsubsection{Outdated Excuse and Arrogance}

Chinese people, especially younger ones, refuse to accept "being hacked" due to their daily exposure to "clichés" like this. Some people from Weibo comment, "It is stupid to use this strategy", "They are insulting our intelligence again", and "This is a convenient strategy". Yutushiyue, a WeChat user, says: "Do you regard the Chinese people as a fool or are you a fool yourself? Even if you are really hacked, you can't say you are hacked." (Note 6) Xinchuangyi, another Wechat user, explains the reason why the strategy is not readily accepted is that the level of knowledge and awareness of the masses have been greatly improved, and this explanation has completely failed to win the trust of the masses. (Note 7) In the interviews, none of the interviewees believes D\&G has been truly hacked. "Outdated" and "excuse" are often present in all the online media comments. In an interview, a student surnamed Li (Oct. 23, 2019) says, "Due to the development of the Internet in China, especially the popularity of social platforms among young people, negative news is always accompanied by a statement that the account has been hacked. It almost becomes a cliché in China." Nowadays, with the development of technology, the mass have a profound understanding of some common routines and expressions used in crisis public relations.

Professor Zheng thinks that D\&G's arrogance can account for their use of this time-consuming, effortless and convenient excuse. As professor Zheng (2019.10. 23) says, "We need eggs but we squeeze the living space of hens because we look down upon hens. $D \& G$ also looks down upon the Chinese because it is so easy for them to make money from the Chines people. It is reluctant to spend time and efforts explaining the insulting words. So it chooses a simple and easy response."

\subsubsection{Speed First}

A WeChat official account comments that once the crisis breaks out, enterprises should seize every minute to deal with the crisis and $D \& G$ should have had a bigger voice by actively releasing information, and then guided the public opinion by clarifying the truth to achieve the purpose of pacifying public opinion. (Note 8) Xinchuangyi, a WeChat user says, "In the era of 'we media', especially with the highly developed network information at home and abroad, the crisis only takes a few hours from fermentation to outbreak, leaving less and less time for public relations. Therefore, it is highly necessary for the public relations team to respond immediately, understand the causes of the crisis and the core problems, then select reasonable response measures." (Note 9)

\subsubsection{Conflict of Civilization}

Public Relations World Magazine, a WeChat official account, mentions this unique interpretation from cultural conflict perspective. "Multinational corporations are faced with people in totally different cultural backgrounds. When they release information that they think is humorous on 'we media' platform, it will produce immeasurable public opinion responses in another culture. In the current economic globalization, the conflict of civilization is the course that 'we media' public relation practitioners must learn, otherwise the harm of secondary crisis is incalculable." (Note 10) 


\subsubsection{Responsibility, Sincerity and Courage}

In the Chinese context, undertaking responsibility ranks highly because it denotes sincerity. Zoeexiao, an Instagram user says, "Your account isn't hacked. If you want to apologize! Do it in a sincere manner." 姐夫李公关 (Note 11) says, “The core of public relations is attitude and responsibility. Even if really hacked, the leader of the enterprise also needs to have the courage to stand up and communicate." "Coward" is a negative word to describe D\&G's behavior. "Shuaiguo" in Chinese means to shirk responsibility. Although SCCT states that when you have no responsibility for the crisis, you can deny it to prove your innocence. 皇太 极 (Note 12), a Zhihu user, says, "You are ignorant because you make promotional video to make fun of China. You are so rude to make insulting words online. You have no courage to bear the responsibility for your insulting words. Above all, you are shameless. People who have the courage to do bad thing but lack the courage to bear the responsibility are the most obscene." We should attach importance to responsibility in dealing with a crisis in the Chinese context.

Chinese people admire and appreciate those who have the courage to take responsibility for mistakes while westerners think admission of guilt can mark the beginning of legal and reputational difficulties to come (Tyler 1997). From the perspective of crisis management, only by being brave enough to take responsibility and showing full honesty to the public can we finally gain public sympathy, understanding, trust and support.

\subsubsection{National Dignity Is Inviolable}

There is one important reason why being hacked is not accepted. In an interview with a student surnamed Xiao (Oct. 23, 2019) in Jilin Police College who was once a solider, she says in an angry manner, "Insulting our country is different from extramarital relationship or something else. Insulting our nation can never be forgiven no matter what response D\&G makes." She expresses the same strong feeling of patriotism as other online platform users' comments. On those platforms, we collected many comments making dirty words to vent anger and even "burning D\&G's clothes" to express their patriotism and nationalism. As 新 传考研真经 (Note 13), an official account says, “There is a group of post-90s network nationalists. Network technology and nationalism are integrated in the process for personal subject construction. This new network nationalism is called 'fan nationalism'. D\&G should realize the seriousness of the situation that those "nationalists" boycott anyone who harms the sacred dignity of the nation. Denial strategy is applied inappropriately in this crisis with strong nationalistic sentiment."

\subsubsection{Over-Reaction}

There are also positive opinions towards the insulting words made by D\&G. In the YouTube clip, a Chinese woman says, "they have no choice but to say 'being hacked' because apology means to owning up to make insulting words." In another YouTube video, Cris, an American man, says in a YouTube video,

"D\&G may have some quarrel with the Vietnam girl (the girl who releases the screenshot). They have a private conversation but the girl is angry in the quarrel so she exposes the 
screenshot with insulting words. The designer is angry too. Every angry man would do something insane. It is understandable. But a brand should not be destroyed just because of the personal performance. Because the quality of clothes from this brand is very good actually, not like other brands which focus on quantity rather than quality. It is a great loss if the whole world boycott the brand just because one person's mistake. A person endures all kinds of hardships to establish a brand, only to lose the brand because of a few words, this is a scary thing. Because when a brand collapses, it is not just the loss of the designer, it is the loss of the brand, but also the number of people who work for the brand and that is a tough thing. If such an event occurs, consumers should be allowed to choose whether to buy or not."

It is clear that Cris thinks Chinese people overreacted to the insulting words and Chinese people make a close relationship between products and the designers. Therefore, Chinese people boycott the brand and its products. However, Cris thinks there is a separation between designers and products because he buys products due to its good quality. There is a controversy about whether or not we should separate the products from designers. In the WeChat official account platform, an account named 旷真 MIC (Note 14) expresses the opposite opinion,

In the Internet era, any brand can no longer rely solely on product advantages and ignore user experience to win future customers, just like traditional marketing thinking. Users are the core of marketing mode in the Internet era, and the so-called fan economy is the user-centered marketing thinking. If the enterprise still maintain the superiority of the product thinking, eventually they will be abandoned by users. So in the Internet era, how should we set up the right brand awareness, establish a complete public relations system? The correct brand awareness is to keep pace with the time because the brand rather than the product leaves impression on users.

When operating in a comparatively collectivistic cultural context like China, a company can never excise its relation with top executives. Collectivist values are associated with an interdependent perspective of the self, where "others become an integral part of the setting, situation, or context to which the self is connected, fitted, and assimilated" (Markus \& Kitayama, 1991). In this case, Gabbana, who made the derogatory comments, is the designer and founder CEO for the company. The cleave point between designer and products may not be readily available. It also has something to do with power distance. In China where the power distance is comparatively higher, the designer and CEO represents the image of the company. As Shunshi Technology Network Public relations Company, an official account, says, "It is fine if the average shop assistant has these problems, but D\&G's biggest problem is that it is the direct leader, the top designer who makes those insulting words, which also makes crisis communication very troublesome."

\subsection{Victimage Strategy}

Victimage is adopted to deal with the non-attendance of Chinese stars in the fashion show. D\&G said in Weibo (Note 15) and Instagram, 
"Our dream was to bring to Shanghai a tribute event dedicated to China which tells us history and vision. It was not simply a fashion show, but something that we created especially with love and passion for China and all the people around the world who loves Dolce \& Gabbana. What happened today was very unfortunate not only for us, but also for all the people who worked day and night to bring this event to life. From the bottom of our hearts, we would like to express our gratitude to our friends and guests."

We isolated comments related to the victimage strategy from topics about D\&G in these social media platforms by searching for key words like "D\&G's show cancelled", "D\&G unfortunate". The category of these comments is listed in Table 7.

According to SCCT, victimage can be adopted when the organization has to take no or medium responsibility for the crisis. In this case, $D \& G$ suffered a financial loss of more than 8 million RMB due to the cancellation of the show. However, according to the comments, this strategy does not produce compassion from Chinese people. On the contrary, the victimage strategy in this case brings negative comments.

First of all, we would like to compare the comments on this response from various platforms. The comments on the microblog pointed out that the response did not mean apology at all, but meant grievance, blame and arrogance. Some also pointed out the language problem that the statement should be made in Chinese rather than English.

In the Zhihu platform, in addition to the above-mentioned grievance, blame and arrogance, users also point out a sense of regret indicated in the statement.

In the official account of WeChat, users also point out that there was no apology for the statement but grievance, arrogance and regret.

In the YouTube platform, users say no apology, but blame in the statement.

The comments on Instagram point out that D\&G tried to play the role of victim and had a strong sense of ethnocentrism.

Facebook users have less comment on the statement, but mainly point to the undesirable side of the victim role he tried to play.

In the interview, professor Zheng analyzes the statement from the language level in detail, which will be discussed in the following analysis. After further categorization, analysis of these comments was divided into two parts.

Table 7. Comments on victimage strategy

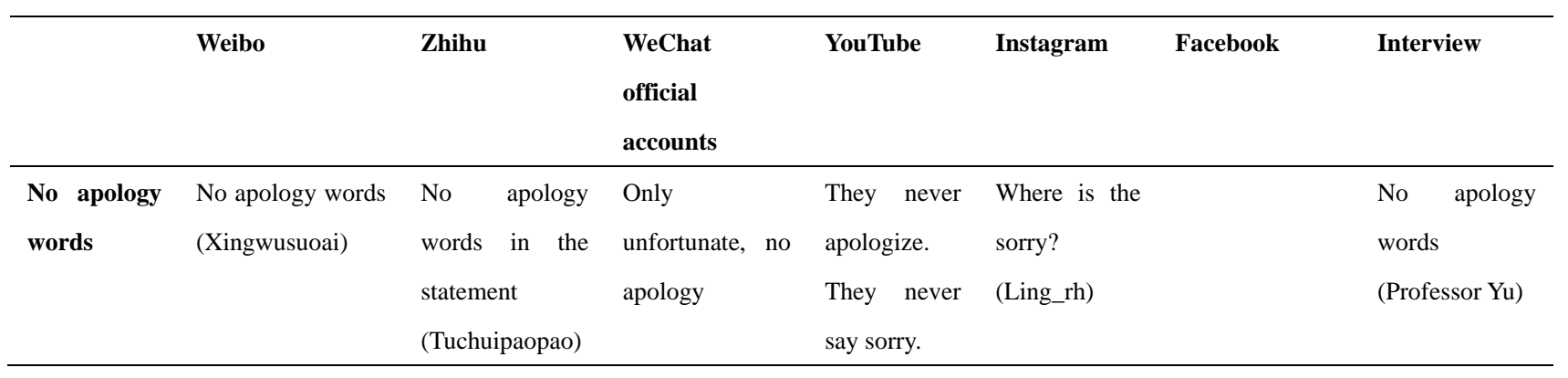




\begin{tabular}{|c|c|c|c|c|c|c|c|}
\hline Grievance & $\begin{array}{l}\text { It sounds like they } \\
\text { has been deeply } \\
\text { wronged } \\
\text { (Chuntiandetutu) }\end{array}$ & $\begin{array}{l}\text { It's more like } \\
\text { D\&G is } \\
\text { courting } \\
\text { international } \\
\text { sympathy and } \\
\text { international } \\
\text { support } \\
\text { (xiacheluantan) }\end{array}$ & $\begin{array}{l}\text { Instead of } \\
\text { apologizing, the } \\
\text { statement } \\
\text { identified itself } \\
\text { as an injured } \\
\text { party. (Anhe } \\
\text { etiquette ) }\end{array}$ & & $\begin{array}{l}\text { Don't be } \\
\text { trying to play } \\
\text { victim. }\end{array}$ & $\begin{array}{l}\text { It was your own } \\
\text { insulting words, } \\
\text { discriminating } \\
\text { video and } \\
\text { arrogant lying } \\
\text { attitude that } \\
\text { ruined your } \\
\text { so-called nice } \\
\text { show and so } \\
\text { many workers } \\
\text { efforts! } \\
\text { (Ziwenwong) }\end{array}$ & $\begin{array}{l}\text { They want to } \\
\text { appear as a } \\
\operatorname{victim}(\mathrm{Yu})\end{array}$ \\
\hline Blame & $\begin{array}{l}\text { This is to blame } \\
\text { us } \\
\text { people. }\end{array}$ & $\begin{array}{l}\text { It feels like the } \\
\text { Chinese bring } \\
\text { their loss. }\end{array}$ & & $\begin{array}{l}\text { Play } \\
\text { emotional. } \\
\text { Employees } \\
\text { suffer due to } \\
\text { the } \\
\text { cancelation } \\
\text { of the show. }\end{array}$ & & & $\begin{array}{l}\text { They blame the } \\
\text { Chinese for } \\
\text { making things } \\
\text { serious, which } \\
\text { led to the } \\
\text { cancellation of } \\
\text { the show. } \\
\text { (Xiao) }\end{array}$ \\
\hline Arrogance & $\begin{array}{l}\text { It seems like } \\
\text { holding a show in } \\
\text { China is looking } \\
\text { upon you Chinese } \\
\text { people. }\end{array}$ & $\begin{array}{l}\text { A sense of } \\
\text { superiority that } \\
\text { springs from } \\
\text { nowhere. (十) }\end{array}$ & $\begin{array}{l}\text { They treated it } \\
\text { with } \\
\text { indifference. } \\
\text { They think } \\
\text { arrogantly that } \\
\text { D\&G has } \\
\text { nothing to do } \\
\text { with it. }\end{array}$ & & $\begin{array}{l}\text { Ethnocentris } \\
\mathrm{m} \text { is the act of } \\
\text { judging } \\
\text { another } \\
\text { culture based } \\
\text { on } \\
\text { preconception } \\
\mathrm{s} \text { that are } \\
\text { found in } \\
\text { values and } \\
\text { standards of } \\
\text { one's own } \\
\text { culture. }\end{array}$ & & $\begin{array}{l}\text { Our dream was } \\
\text { to bring } \\
\text { shanghai" is } \\
\text { what God says } \\
\text { to people. } \\
\text { (Professor } \\
\text { Zheng) }\end{array}$ \\
\hline Language & $\begin{array}{lr}\text { Are } & \text { you } \\
\text { apologizing } & \text { in } \\
\text { English } & \text { for } \\
\text { Americans? } & \\
\text { ( Yanzhaoer) }\end{array}$ & $\begin{array}{l}\text { D\&G did not } \\
\text { add a statement } \\
\text { in Chinese on } \\
\text { Chinese social } \\
\text { media, which } \\
\text { presumably was } \\
\text { not meant for } \\
\text { Chinese people. }\end{array}$ & & & & & \\
\hline Regret & & $\begin{array}{l}\text { There is only } \\
\text { regret in the }\end{array}$ & $\begin{array}{l}\text { There is no } \\
\text { apology only }\end{array}$ & & & & \\
\hline
\end{tabular}


statement for regret for the

the cancellation show.

of the show

\subsubsection{Victimage Indicates Arrogance and Superiority}

The tone of grievance and blame in the statement can indicate arrogance. Yutushuyue (Note 16) from the WeChat official account reinterprets the statement, "Are you idiots? I condescended to Shanghai to hold the exhibition. It is so obvious that I want to make money. It is your fault to sense the discrimination! It is your fault that the show is cancelled. My only fault is that my discrimination is too obvious!" Then Yutushuyue further claims, "It's the legendary 'suicidal apology.' The ability of $D \& G$ and its designers to 'show discrimination against a nation' and 'show self-conceit, arrogance and ignorance' is at its peak in this statement."

The absence of "sorry" to the Chinese people also indicates D\&G's arrogance. 大成商道 (Note 17), a WeChat official account says, "In this statement, the word 'gratitude' is targeted at the friends and guests who made preparation for the show. There is no apology made to China and Chinese people." There are two explanations for this situation. The first one is that D\&G still fails to realize the emotional distress brought to Chinese people so they only show the gratitude to those who made efforts for the show. The second one is that D\&G shows quite arrogant attitude, which will be explained by professor Zheng from the language angle.

In the interview, professor Zheng (Oct. 23, 2019) carefully analyzes the words in victimage statement, "This statement is like what God says to his people. The words 'bring', 'tribute', 'tell our history and vision' can indicate this. For example, God would say 'I will bring you light, I will bring you food, and I will bring you life'. They say 'we' are unfortunate and then the workers, but they do not mention the Chinese people. They express their gratitude to friends and customers but not to the Chinese people." He says, "D\&G thinks that you Chinese people are not my friends or my clients. What is your qualification to judge and let us apologize?" Zheng points out this arrogant attitude between the company's words in the statement. D\&G's statement indicates that the show is a charity to the Chinese people and it is such a pity for the Chinese people missing the show. D\&G's mistake lies in overlooking China from the very beginning. D\&G thinks that the Chinese people should have looked up to D\&G. Intercultural communication demands equality and respect. D\&G's response reveals that they feel they are superior to the Chinese people.

\subsubsection{Victimage Indicates a Self-Oriented or Self-Centered Mindset}

"Self-centered" means being limited to or caring only about yourself and your own needs. Grievance and blame can reflect their self-centered mindset. As professor Yu (Oct. 24, 2019) says, "The statement shows a complaint tone with the word 'unfortunate' that our Chinese people's overreaction leads to their loss of money. D\&G does not mention the damage brought to Chinese people.” A Zhihu user 瞎扯乱谈 (Note 18) says, “The statement is more likely to show that D\&G is seeking international sympathy and support for itself, while ignoring the harm it has done to Chinese consumers." Liu Run, former director of Microsoft, 
says, "The essence of crisis communication is public sentiment management." In many cases, the public is very concerned about whether enterprises care about their feelings. Therefore, enterprises should think from the perspective of the public and treat the public as victims.

However, an Australian teacher, T says, "For D\&G, China is more powerful than the company. The reactions of the Chinese public leads to the cancellation of the show. Therefore, they think they are the victim." From D\&G's standpoint, there is huge damage due to the cancellation of the show. From Chinese people's standpoint, the insulting words offend national dignity and hurt their feelings. Intercultural crisis communication requires empathy and a public-oriented mindset to deal with a crisis. Even if the public has a certain responsibility in the crisis, the enterprise should not place the blame on the public; otherwise, it will only deepen the contradiction and cause public antipathy, which is not conducive to solving problems.

\subsection{Apology Strategy}

D\&G finally released their apology video six days after the original promotional video was released. At the beginning, it was released on the Weibo platform (Note 19). Here is the script.

"Over the past few days, we have been seriously reflecting that our love for China is as strong as ever. Countless visits have deepened our love for Chinese culture. Of course, we still have a lot to learn. We must apologize for the mistake we made in our previous statement. We will never forget this experience and lesson, and this kind of thing will never happen again. At the same time, we will do our best to better understand and respect Chinese culture. Finally, we ask for your forgiveness sincerely. I am sorry. We will never forget this experience and lesson, and it will never happen again. At the same time, we will do our best to better understand and respect Chinese culture. Finally, we ask for your forgiveness sincerely. Sorry (in Chinese)."

There are various comments concerning this apology video in Weibo, Zhihu, official accounts, Facebook, Instagram, YouTube and interviews. Criticism towards the video focused on many aspects. According to SCCT, an apology should be adopted when the organization has to take full responsibility for the crisis in the preventable cluster. The preventable cluster has very strong attributions of crisis responsibility and the event is considered purposeful (Coombs and Holladay 2002). D\&G finally recognized their mistake and made the apology video. However, the negative comments still far outweigh the positive comments. Comments on apology video is listed in Table 8.

Weibo users evaluate the apology video from six aspects, including the special offer of apology for Chinese, the inconsistent strategy, time, purpose, content and external performance of the apology.

Zhihu users mention that the special offer for Chinese, the inconsistency, as well as the purpose of the apology, the content of the apology, and the external performance. 
Users of WeChat official account emphasize the importance of action and the importance of authority confirmation besides the above aspects.

WeChat users emphasize the importance of action and the authority affirmation.

The key points of the interview include the special offer, the inconsistent strategy, and untimeliness, the purpose of the apology, the external performance, and the importance of action.

A YouTube user, Lao lei, analyzes in detail his unique view about being forced to apologize, which will be described in detail below.

Few comments collected on Instagram and Facebook are mainly from the special offer, time and external performance to interpret the apology video.

Table 8. Comments on apology strategy

\begin{tabular}{|c|c|c|c|c|c|c|c|}
\hline & Weibo & Zhihu & $\begin{array}{l}\text { WeChat official } \\
\text { account }\end{array}$ & YouTube & Instagram & Facebook & Interview \\
\hline $\begin{array}{l}\text { Special offer } \\
\text { for China }\end{array}$ & $\begin{array}{l}\text { The video is } \\
\text { not released in } \\
\text { Instagram or } \\
\text { Twitter. } \\
\text { (Luxiaolin) }\end{array}$ & $\begin{array}{l}\text { The apology did } \\
\text { not appear on } \\
\text { Instagram, the } \\
\text { social } \\
\text { networking site } \\
\text { where the } \\
\text { incident took } \\
\text { place. } \\
\text { (Dongyun) }\end{array}$ & $\begin{array}{l}\text { Unlike the } \\
\text { second response, } \\
\text { the video of the } \\
\text { apology was } \\
\text { posted only on } \\
\text { Weibo. (Anhe } \\
\text { etiquette) }\end{array}$ & & $\begin{array}{l}\text { A sincere } \\
\text { apology must be } \\
\text { made, } \\
\text { specifically to } \\
\text { the Chinese by } \\
\text { naming them on } \\
\text { Instagram. } \\
\text { (Jayjayjayjayden } \\
\text { ) }\end{array}$ & & \\
\hline $\begin{array}{l}\text { Consistent } \\
\text { strategy }\end{array}$ & $\begin{array}{l}\text { Isn't it being } \\
\text { hacked? So } \\
\text { you admit you } \\
\text { didn't hacked } \\
\text { before? } \\
\text { (Qiuminshsha } \\
\text { nshenche) }\end{array}$ & $\begin{array}{l}\text { At the } \\
\text { beginning, you } \\
\text { deny it. Now } \\
\text { you admit it. } \\
\text { (Qichacha) }\end{array}$ & & $\begin{array}{l}\text { I think their } \\
\text { account has } \\
\text { been hacked } \\
\text { again. } \\
\text { (Christopher } \\
\text { Wu) }\end{array}$ & & & $\begin{array}{l}\text { It's hard to believe that } \\
\text { your apology is sincere, } \\
\text { in contrast to your } \\
\text { previous response. } \\
\text { (Wang) }\end{array}$ \\
\hline Untimeliness & $\begin{array}{l}\text { It is too late to } \\
\text { apologize. } \\
\text { (Zhangyuqing) }\end{array}$ & & $\begin{array}{l}\text { It is too late. } \\
\text { (Zhangci) }\end{array}$ & & $\begin{array}{l}\text { Too late and too } \\
\text { fake. (Yannick } \\
\text { xia) }\end{array}$ & $\begin{array}{l}\text { It is too late to } \\
\text { apologize. (Boni } \\
\text { lee) }\end{array}$ & $\begin{array}{l}\text { It is too late. Information } \\
\text { is transmitted so fast. } \\
\text { Now the situation a little } \\
\text { out of control. (Wang) }\end{array}$ \\
\hline Purpose & $\begin{array}{l}\text { Are you } \\
\text { apologizing to } \\
\text { our people or } \\
\text { our money? } \\
\text { (Tomatofrydan } \\
\text { ke) }\end{array}$ & $\begin{array}{l}\text { D\&G begins to } \\
\text { bow for Chinese } \\
\text { market. } \\
\text { (Zhuoxiaoyu) }\end{array}$ & $\begin{array}{l}\text { And when all of } \\
\text { China's } \\
\text { e-commerce } \\
\text { platforms } \\
\text { removed their } \\
\text { products, Dolce } \\
\text { \& Gabbana may }\end{array}$ & $\begin{array}{l}\text { They are } \\
\text { apologizing to } \\
\text { the money, } \\
\text { not the } \\
\text { people. } \\
\text { (Donter Tan) }\end{array}$ & & & $\begin{array}{l}\text { Because their interests } \\
\text { were threatened, they had } \\
\text { to apologize to reduce the } \\
\text { loss. }(\mathrm{Hu})\end{array}$ \\
\hline
\end{tabular}




\begin{tabular}{|c|c|c|c|c|}
\hline & & $\begin{array}{l}\text { really panic. } \\
\text { (Zhangci) }\end{array}$ & & \\
\hline Content & $\begin{array}{l}\text { I don't think The apology } \\
\text { that cursing a video defends } \\
\text { country has the promotional } \\
\text { anything to do video by the } \\
\text { with "cultural excuse of } \\
\text { differences". cultural } \\
\text { (Jisiling) } \\
\text { (Dong Yun) }\end{array}$ & $\begin{array}{l}\text { The apology did } \\
\text { not respond to } \\
\text { the core } \\
\text { question. (拖鞋 } \\
\text { 哥新传考研) }\end{array}$ & $\begin{array}{l}\text { They keep } \\
\text { saying about } \\
\text { this cultural } \\
\text { difference } \\
\text { thing, but } \\
\text { never mention } \\
\text { the racist } \\
\text { comment. } \\
\text { (Fangxu sun) }\end{array}$ & \\
\hline $\begin{array}{l}\text { External } \\
\text { performance }\end{array}$ & $\begin{array}{l}\text { You apologize The one on the } \\
\text { and look at the right is staring at } \\
\text { autocue. the autocue, } \\
\text { There's no } 90 \text { reciting a script. } \\
\text { degree bow. (Black rabbit in } \\
\text { (Mengge or Zhanghua) } \\
\text { mengg) }\end{array}$ & $\begin{array}{l}\text { The both } \\
\text { founders dress } \\
\text { casual clothes } \\
\text { rather than } \\
\text { formal clothes. } \\
\text { (Anhe etiquette) }\end{array}$ & $\begin{array}{l}\text { All I see is Please be } \\
\text { your apology sincere. Don't } \\
\text { needs keep look at the } \\
\text { watching your autocue. } \\
\text { ad autocue. (Yuhaiyang520) } \\
\text { (Chuck with } \\
\text { the c) }\end{array}$ & $\begin{array}{l}\text { One of the designers } \\
\text { raised his hand, a gesture } \\
\text { of disdain. (Professor Yu) }\end{array}$ \\
\hline $\begin{array}{l}\text { Act speaks } \\
\text { louder }\end{array}$ & & $\begin{array}{l}\text { An apology } \\
\text { without action is } \\
\text { not an apology. } \\
\text { (Aozhoudaoju) }\end{array}$ & & $\begin{array}{l}\text { They need to respond } \\
\text { with concrete actions, } \\
\text { such as changing } \\
\text { unreasonable language in } \\
\text { the video. }(\mathrm{Hu})\end{array}$ \\
\hline $\begin{array}{l}\text { Authoritative } \\
\text { confirmation }\end{array}$ & & $\begin{array}{l}\text { However, after } \\
\text { dolce \& } \\
\text { Gabbana made } \\
\text { an official } \\
\text { apology to the } \\
\text { whole nation, it } \\
\text { failed to get a } \\
\text { positive } \\
\text { response from } \\
\text { the credible } \\
\text { media and lost } \\
\text { the "initiative" } \\
\text { to deal with the } \\
\text { incident. } \\
\text { (Chuangzhi } \\
\text { technology) }\end{array}$ & & \\
\hline
\end{tabular}

\subsubsection{The Content of Apology: Cultural Misunderstanding or Value?}

D\&G diverts their mistakes on cultural misunderstanding without mentioning of the promotional video and insulting words. Instead of acknowledging the inappropriateness of his 
insulting remarks and propaganda video, the CEO of D\&G used the excuse of "our cultural misunderstanding”. As a WeChat official account 拖鞋哥新传考研 (Note 20) says, “He attributed the crisis to 'cultural misunderstanding', which is to explain the online debate caused by the previous promotional video, but he did not talk about the real trigger of the crisis, that is the insulting remarks, not to mention explaining the previous statement 'being hacked'."

$D \& G$ evaded explaining the insulting words by the designer. Some people expressed their opinion that D\&G should reflect on themselves from their organization's value. As a Zhihu user Jiefuligongguan says, "The core of crisis communication is attitude and responsibility. Value is the cornerstone of an enterprise at any time in a crisis." A Zhihu user 姐夫李公关 (Note 21) gives a revised version for $\mathrm{D} \& \mathrm{G}$,

"We did not fully consider the sensitivity of different cultures around the world and completely ignored the pride of Chinese people in their own nation and culture. While reviewing our creativity, we should also reexamine our values. Although the main founders of the company have emotional impulses in the social media conversation, the appearance of such comments also reflects our immature and unsound values, and our unclear understanding of the moral standards that we should embody as a global enterprise."

Organizations need to reflect on their cultural value in crisis communication and the price they should pay for their behavior to get the understanding of the public. Enterprise values refer to the value orientation of enterprises and their employees, the basic beliefs and goals that enterprises advocate in the course of pursuing business success. Apology is the reflection of corporate values. The content of any apology should be elevated to a reflection on values rather than at the superficial level of cultural misunderstanding.

\subsubsection{Manner of Apology: Sincerity in Apology}

Sincere attitude plays an important role in apology. Large amounts of comments referred to the insincerity in D\&G's apology video. A number of factors contribute to insincerity in the apology video. Many people pointed out that the two founders dress pajamas-like clothes for this video. On formal business occasions, they should wear formal clothes when apologizing to show sincerity. Chuck with the c, a YouTube user says, "All I see is your apology needs keep watching your ad autocue." Professor Yu (Oct. 24, 2019) points out the insincerity from gestures, "One of the designer makes a dismissive gesture when he says sorry." A student surnamed Pan (Oct. 23, 2019) points out their insincerity because they release the video in Instagram, Facebook and YouTube three hours later. Pan says, "Maybe D\&G is afraid that others look down upon them as a flunkey of Chinese if they release the video on other media platforms.” A Zhihu user 九九一十八 (Note 22) says, “Japanese people still know how to bow when they apologize. You just look at the autocue and read a copy."

When operating in a high-context culture like China, people are very sensitive to implicit information. It is desirable for them to learn the Chinese culture about apology to indicate their sincerity. For example, standing and bowing to apologize and paying attention to details 
like dress code to convey implicit information. And they can try to apologize through a variety of network media channels to expand the impact of the apology statement.

What's more, sincerity cannot be achieved only by words. As professor Zheng (Oct. 23, 2019) says, "Language doesn't make any sense. The key is to do something. The key is sincerity in apology. We can measure the sincerity from three indicators: time, efforts and money." D\&G claims that they respect Chinese culture. In intercultural crisis communication, organizations need to learn how to apologize in accordance to a country's culture. To further demonstrate their sincerity in Chinese context, they can donate money to run-down areas in China because money and efforts are indicators of their sincerity.

\subsubsection{The Untimeliness of Apology}

The apology video was released on November 23, 2018, 6 days after the promotional video released. The apology missed the best time of crisis communication. It is criticized by the public as being too late. 章辞 (Note 23), a WeChat official account, points out that When D\&G's products are off the shelves in all major domestic e-commerce platforms, D\&G may have really panicked, which means that Chinese people are boycotting the brand and no sales revenue. If things cannot be solved successfully, $D \& G$ may say goodbye forever. The two founders' apology is so late that Chinese people doubt they apologize to curb the economic loss in the Chinese market. The untimeliness of the apology contributes to "a culture of being forced to apologize", which is mentioned by Lao lei, a German YouTube user. Lao lei says, "I think they are forced to apologize. It seems like they are putting on a play. It reminds me of my childhood. When I was a kid, my brother, sister, and I bullied each other, but I did not want to apologize to my brother and sister at all although my mother forced me to do so." A WeChat official account 澳洲道具 (Note 24) says, “The response must be fast, and the "golden four hours" in crisis communication must be grasped. Once the brand loses the customers' heart, it is difficult to acquire again." Apology by pressure rather than by heart is insincere. It is not an overemphasis that the time of public relations is related to the life and death of a brand image. Brand should understand that only by actively eliminating misunderstandings could we regain the confidence of customers."

\subsubsection{Inconsistent Strategy}

This case gives us a lesson that the denial strategy and apology cannot be used at the same event. Many people find it hilarious that D\&G says they are hacked and then makes apology. A student surnamed Wang (Oct. 23, 2018) says, "It is a sharp contrast between denial at the first time and the final apology. It is hard for us to believe your apology is sincere." Another student surnamed Zheng (Oct. 23, 2018) says, "If they make apology at the first time, they don't have to make second and third responses. Nevertheless, they do not. So they are forced to apologize due to economic pressure and pressure from the public." An enterprise should unify all members to speak with one voice to avoid loss of control, disorder and even contradiction, thus aggravating public confusion and complicating the problem. 


\section{Conclusion}

In this paper, we analyze the online posts concerning $D \& G$ case from major social platforms to unveil the attitudes of different stakeholders in an attempt to generalize appropriate crisis response strategy within SCCT framework. In recent years, social media is booming, which has had a significant impact on many industries. In the field of crisis communication, social media not only becomes the source of information trusted by the public, but also provides more channels for communication between the public and the organization, and it brings great convenience for organizational crisis management. At the same time, social media also intensifies the breadth, depth and intensity of crisis spread.

As for the theoretical implications, firstly, this study has emphasized the importance of achieving glocalization of crisis communication through investigating D\&G's case in China, which is in line with Derek Lehmberg and Jeff Hicks's argument that using glocalization for the internationalizing of crisis communication avoids imposing western frameworks and interpretations onto non-western crisis situations (2018). Secondly, this study provides meaningful insights and implications to promote the situational crisis communication theory. Under the denial strategy, public regard this strategy as being outdated, demonstrating superiority and lack of responsibility. Moreover, denial strategy is inappropriate because national dignity is inviolable concerning the nature of the crisis. In addition, as illustrated in the SCCT strategy, prior history should be considered when evaluating the seriousness of a crisis. An American YouTube user Cris also mentions overreaction as he separates products from designer of the products. It is evident that Chinese people regard these two factors as a whole. Under the victimage cluster, D\&G portrays itself as a victim, which indicates arrogance and self-centered mindset. However, intercultural crisis communication presupposes respect and equality. Under the apology video, in the content of apology, most responses criticize that $\mathrm{D} \& \mathrm{G}$ attributes their mistakes to cultural misunderstanding. In the manner of the apology, D\&G's insincerity is present in the gesture, dress code, etiquette, untimeliness, etc. What' more, most responses point out the inconsistency of the strategy, so denial and apology strategies cannot be applied in one case.

Moving beyond the case of $D \& G$, intercultural crisis communication is just one of numerous fields where scholars and practitioners working from different perspectives to generalize more favorable outcome. Making progress in this respect calls for exploration and experimentation with new and different approaches.

\section{References}

Benoit, W. L. (1997). Image repair discourse and crisis communication. Public Relations Review, 23(2), 177-186. https://doi.org/10.1016/S0363-8111(97)90023-0

Berelson, B. (1952). Content analysis in communication research. Glencoe, IL: The Free Press.

Breuch, L.-A. K. (2015). Glocalization in website writing: The case of MNsure and imagined/actual audiences. Computers and Composition, 38, 113-125. https://doi.org/10.1016/j.compcom.2015.09.009 


\section{Al Macrothink}

International Journal of Linguistics

ISSN 1948-5425

2021, Vol. 13, No. 2

Chang, J. C., \& Zhu, R. T. (2016). Analysis on the impact of "glocalization" strategy on overseas investment in retail industry. Business Economics Research, 24, 5-8.

Chen, J., He, R. Q., \& Dai, Z. Q. (2019). Self-presentation and group characteristics of Zhihu users-----Research based on big data. Young Journalist, 18, 50-51.

Cheng, Y., \& Lee, C.-J. (2018). Online crisis communication in a post-truth Chinese society: Evidence from interdisciplinary literature. Public Relations Review. https://doi.org/10.1016/j.pubrev.2019.101826

Coombs, W. T. (2006). The protective powers of crisis response strategies managing reputational assets during a crisis. Journal of Promotion Management, 12, 241-260. https://doi.org/10.1300/J057v12n03_13

Coombs, W. T. (2007). Protecting organization reputations during a crisis: The development and application of situational crisis communication theory. Corporate Reputation Review, 10(3), 163-176. https://doi.org/10.1057/palgrave.crr.1550049

Coombs, W. T., \& Holladay, S. J. (2002). Helping crisis managers protect reputational assets: Initial tests of the Situational Crisis Communication Theory. Management Communication Quarterly, 16(2), 15-186. https://doi.org/10.1177/089331802237233

Coombs, W. T., \& Laufer, D. (2018). Global crisis management - Current research and future directions. Journal of International Management, 24, 199-203. https://doi.org/10.1016/j.intman.2017.12.003

Crump, L. (2015). Analyzing complex negotiations. Negotiation Journal, 31(2), 131-153. https://doi.org/10.1111/nejo.12086

Dameri, R. P., Benevolo, C., Veglianti, E., \& Li, Y. (2019). Understanding smart cities as a glocal strategy: A comparison between Italy and China. Technological Forecasting \& Social Change, 142, 26-41. https://doi.org/10.1016/j.techfore.2018.07.025

Dash, A. K. (2016). A multimodal discourse analysis of glocalization and cultural identity in three Indian TV commercials. Discourse \& Communication, 10(3), 209-234. https://doi.org/10.1177/1750481315623892

Dhanesh, G. S., \& Sriramesh, K. (2018). Culture and crisis communication: Nestle India's Maggi noodles case. Journal of International Management, 24, 204-214. https://doi.org/10.1016/j.intman.2017.12.004

Feng, W. (2018). Communicating discourses with Chinese characteristics: A case study of the CCTV documentary - A Bite of China. Journal of Shanxi University (Philosophy and social sciences), 41(04), 81-86.

Hofstede, G. (1991). Culture's consequences: Comparing values, behaviors, institutions and organizations across nations. Shanghai Foreign Language Education Press. 
Hu, Y., \& Pang, A. (2018). The indigenization of crisis response strategies in the context of China. Chinese Journal of Communication, 11(1), 105-128. https://doi.org/10.1080/17544750.2017.1305978

Huang, Y.-H. C., Wu, F., \& Cheng, Y. (2016). Crisis communication in context: Cultural and political influences underpinning Chinese public relations practice. Public Relations Review, 42, 201-213. https://doi.org/10.1016/j.pubrev.2015.11.015

Huang, Y.-H., Lin, Y.-H., \& Su, S.-H. (2005). Crisis communicative strategies in Taiwan, category, continuum, and cultural implication. Public Relations Review, 31(2), 229-238. https://doi.org/10.1016/j.pubrev.2005.02.016

Jiang, J., Huang, Y.-H., Wu, F., Choy, H.-Y., \& Lin, D. (2015). At the crossroads of inclusion and distance: Organizational crisis communication during celebrity-endorsement crises in China. Public Relations Review, 41, 50-63. https://doi.org/10.1016/j.pubrev.2014.11.003

Jijon, I. (2017). The moral glocalization of sport: Local meanings of football in Chota Valley, Ecuador. International Review for the Sociology of Sport, 52(1), 82-96. https://doi.org/10.1177/1012690215572854

Khondker, H. H., \& Robertson, R. (2018). Glocalization, consumption, and cricket: The Indian Premier League. Journal of Consumer Culture, 18(2), 279-297. https://doi.org/10.1177/1469540517747094

Ki, E. J., \& Nekmat, E. (2014). Situational crisis communication and interactivity: Usage and effectiveness of Facebook for crisis management by Fortune 500 companies. Computers in Human Behavior, 35, 140-147. https://doi.org/10.1016/j.chb.2014.02.039

Kim, S., Zhang, X. A., \& Zhang, B. W. (2016). Self-mocking crisis strategy on social media: Focusing on Alibaba chairman Jack Ma in China. Public Relations Review, 42, 903-912. https://doi.org/10.1016/j.pubrev.2016.10.004

Kracauer, S. (1952). The challenge of qualitative content analysis. Public Opinion Quarterly, 16, 631-642. https://doi.org/10.1086/266427

Laufer, D., Garrett, T. C., \& Ning, B. (2018). The moderating role of power distance on the reaction of consumers to the $\mathrm{CEO}$ as a spokesperson during a product harm crisis: Insights from China and South Korea. Journal of International Management, 24, 215-221. https://doi.org/10.1016/j.intman.2017.12.002

Lehmberg, D., \& Hicks, J. (2018). A 'glocalization' approach to the internationalizing of crisis communication. Business Horizons, 61, 357-366. https://doi.org/10.1016/j.bushor.2018.01.002

Long, X. N., \& Fan, P. (2018). Localization strategy and global operation of ZEE TV India and its inspiration. TV Research, (06), 86-88. 
Lu, Y. (2007). On the marketing strategy model of the Disneyland in Asian market: A case of the Disneyland Hong Kong. Journal of Hubei University (Philosophy and Social Science), 34(3), 108-110.

Lyu, J. C. (2012). A comparative study of crisis communication strategies between Mainland China and Taiwan: The melamine-tainted milk powder crisis in the Chinese context. Public Relations Review, 38, 779-791. https://doi.org/10.1016/j.pubrev.2012.07.003

Markus, H. R., \&Kitayama, S. (1991). Culture and the self: implications for cognition, emotion, and motivation. Psychological Review, 98(2), 224-253. https://doi.org/10.1037/0033-295X.98.2.224

Matusitz, J. (2015). Bharti-Wal-Mart: A glocalization experience. Journal of Asian and African Studies, 50(1), 83-95. https://doi.org/10.1177/0021909613512948

Merriam, S. B. (1998). Qualitative research and case study applications in education. San Francisco, CA: Jossey-Bass.

Ngai, C. S. B., \& Jin, Y. (2016). The effectiveness of crisis communication strategies on Sina Weibo in relation to Chinese publics' acceptance of these strategies. Journal of Business and Technical Communication, 30(4), 451-494. https://doi.org/10.1177/1050651916651907

Oliveira, M. D. F. (2013). Multicultural environments and their challenges to crisis Communication. The Journal of Business Communication, 50(3), 253-277. https://doi.org/10.1177/0021943613487070

Ren, Z. J., Zhang, P., Li, S. C., Lan, Y. X., Xia, Y. X., \& Cui, Y. C. (2019). Analysis of emotion evolution of emergencies based on Weibo data mining: Taking "8.12 Accident in Tianjin" as an example. Journal of Intelligence, 38(02), 140-148.

Ritzer, G. (2003). The Globalization of Nothing. Johns Hopkins University Press, 23(2), 189-200. https://doi.org/10.1353/sais.2003.0053

Roudometof, V. (2016). Theorizing glocalization: Three interpretations. European Journal of Social Theory, 19(3), 391-408. https://doi.org/10.1177/1368431015605443

Ru, X. Z., \& Hu, Y. (2016). Zhihu: A rational experimental field in the Public domain of Internet in China. Journalism Lover, (02), 20-24.

Rugman, A., \& Hodgetts, R. (2001). The end of global strategy. European Management Journal, 19(4), 333-343. https://doi.org/10.1016/S0263-2373(01)00035-4

Salazar, N. B. (2005). Tourism and glocalization "Local" tour guiding. Annals of Tourism Research. Annals of Tourism Research, 32(3), 628-646. https://doi.org/10.1016/j.annals.2004.10.012

Schreier, M. (2012). Qualitative content analysis in practice. London, UK: Sage.

Shi, X. 2013. The glocalization of English: A Chinese case study. Journal of Developing Societies, 29(2), 89-122. https://doi.org/10.1177/0169796X13480442 
Simi, D. (2017). Glocalization of subway in India: How a US giant has adapted in the Asian subcontinent. Journal of Asian and African Studies, 52(5), 573-585. https://doi.org/10.1177/0021909615596764

Soulard, J., McGehee, D. C., \& Stern, M. (2019). Transformative tourism organizations and glocalization. Annals of Tourism Research, 76, 91-104. https://doi.org/10.1016/j.annals.2019.03.007

Sun, J. (2006). "Triangulation" as a combination of qualitative research and quantitative research: a review of international studies. Social Sciences in Nanjing, (10), 122-128.

Tang, R. (2020). The development potential analysis of WeChat official account based on the perspective of communication. View on Publishing, (10), 76-78.

Tang, X. M., \& Lai, S. Q. (2017). Research on the response of online public opinion based on the SCCT_ - the case of "Cancer Teacher Dismissal". Journal of Intelligence, 36(07), 96-127.

Tyler, L. (1997). Liability means never being able to say you're sorry: Corporate guilt, legal constraints, and defensiveness in corporate communication. Management Communication Quarterly, 11(1), 51-73. https://doi.org/10.1177/0893318997111003

Wang, Q. J., \& Zhang, J. (2017). The analysis of the characteristics of ontology, subject and transmission of Micro-Blog comments. Editorial Friend, (09), 59-62.

Wang, Y. J., \& Laufer, D. (2019). How does crisis management in China differ from the West? : A review of the literature and directions for future research. Journal of International Management. https://doi.org/10.1016/j.intman.2019.100708

Wu, D. Y. (2017). Glocal strategies by cosmopolitan in China. Foreign Languages and Their Teaching, (03), 62-148.

Wu, X. Y., \& Zhang, X. Y. (2015). The strategies of multinational service companies' glocalization in Chinese market: A study of the big four accounting firms. Nankai Journal (Philosophy, Literature and Social Science Edition), (04), 64-76.

$\mathrm{Wu}$, Y.-C. (2013). The examination and reflection of Pattern-Matching between "Crisis Situation" and "Response Strategy" in Taiwan's crisis rhetorical studies: A meta-analysis. Chinese Journal of Journalism \& Communication, 35(05), 33-42.

Wu, Z. Y. (2018). The Evaluation Model of traditional News media's Weibo influence -- An empirical study based on principal component analysis. Public Communication of Science \& Technology, 10(01), 146-147.

Yang, Z. L., \& Jiang, L. (2015). Managing corporate crisis in China: Sentiment, reason, and law. Business Horizons, 58(2), 193-201. https://doi.org/10.1016/j.bushor.2014.11.003

Yin, R. K. (2009). Case study research: Design and methods (4th ed.). Los Angeles, CA: Sage. 


\section{I Macrothink}

International Journal of Linguistics

ISSN 1948-5425

2021, Vol. 13, No. 2

Yuan, E. J., Feng, M., \& Danowski, J. A. (2013). "Privacy" in semantic networks on Chinese social media: The case of Sina Weibo. Journal of Communication, 63, 1011-1031. https://doi.org/10.1111/jcom.12058

Zhao, M. (2013). Beyond cops and robbers: The contextual challenge driving the multinational corporation public crisis in China and Russia. Business Horizons, 56(4), 491-501. https://doi.org/10.1016/j.bushor.2013.03.006

Zhou, L. J., \& Shin, J.-H. (2017). Does stealing thunder always work? A content analysis of crisis communication practice under different cultural settings. Public Relations Review, 43, 1036-1047. https://doi.org/10.1016/j.pubrev.2017.08.004

Zhu, L., Dahalli, D. A., \& Zhang, A. (2017). Social media and culture in crisis communication: McDonald's and KFC crises management in China. Public Relations Review, 43, 487-492. https://doi.org/10.1016/j.pubrev.2017.03.006

\section{Notes}

Note

1.

https://weibo.com/1974576991/H3GVw9YMc?from=page_1002061974576991_profile\&wvr $=6 \& \bmod =$ weibotime $\&$ type $=$ comment\#_rnd1595517655972

Note

https://weibo.com/2803301701/H3Imklkxg?from=page_1002062803301701_profile\&wvr=6 \&mod=weibotime\&type=comment\#_rnd1595517499543

Note 3. https://weibo.com/tv/show/1034:4309516506863697?from=old_pc_videoshow

Note 4. https://weibo.com/u/2019842447

Note 5. https://www.zhihu.com/question/303137080/answer/536258689

Note

6. http://mp.weixin.qq.com/s?_biz=MzUxOTA4MDg3Mg==\&mid=2247483866\&idx=1\&sn= a25008ab5aa8d15b2866e9faef72e462\&chksm=f9fe5f1dce89d60b0f09774d65c7f7a3dae30d5 a0d93354e3 cad0cc7ea968add56facef93062\& mpshare $=1 \&$ scene $=23 \&$ srcid=07234alvZE4tc5 gE8QTpxhIw\&sharer_sharetime $=1595519971926 \&$ sharer_shareid=804c154d00cb9fad2b648 3d58bdd1e $5 \mathrm{~b} \# \mathrm{rd}$

Note

http://mp.weixin.qq.com/s?_biz=MjM5MTUxNzMxMQ==\&mid=2649986329\&idx=1\&sn= 638f098debad50bc0ae71e25ee5ec2d9\&chksm=beb36a0989c4e31f9dd542f5966d78b661e58 3 ec1a37baa56a1154b078da488f3ec60d7d9eee \&mpshare $=1 \&$ scene $=23 \&$ srcid $=07241 \mathrm{~N} 4 \mathrm{Azm}$ HgHUsqrE9JFLey\&sharer_sharetime $=1595605661275 \&$ sharer_shareid $=804 \mathrm{c} 154 \mathrm{~d} 00 \mathrm{cb} 9 \mathrm{fad} 2$ b6483d58bdd1e5b\#rd

Note

8. http://mp.weixin.qq.com/s?_biz=MzA4MDgzMTEzMw==\&mid=2649499776\&idx=2\&sn= 
dca9c5685ea6facfe1cb1880774636c5\&chksm=8786bf72b0f13664953f1a0a3bd432b86fe38f2 6df7df17f9d252bbdc4bcf9e8b7932f2aff78\&mpshare=1\&scene=23\&srcid=07231DaLnD4PiF ptbOgDnmO6\&sharer_sharetime $=1595519920074 \&$ sharer_shareid $=804 \mathrm{c} 154 \mathrm{~d} 00 \mathrm{cb} 9 \mathrm{fad} 2 \mathrm{~b} 64$ 83d58bdd1e 5b\#rd

Note

9. http://mp.weixin.qq.com/s?_biz=MjM5MTUxNzMxMQ==\&mid=2649986329\&idx=1\&sn= 638f098debad50bc0ae71e25ee5ec2d9\&chksm=beb36a0989c4e31f9dd542f5966d78b661e58 3ec1a37baa56a1154b078da488f3ec60d7d9eee \&mpshare $=1 \&$ scene=23\&srcid=07241N4Azm HgHUsqrE9JFLey\&sharer_sharetime $=1595605661275 \&$ sharer_shareid=804c154d00cb9fad 2 b6483d58bdd1e5b\#rd

Note

10. http://mp.weixin.qq.com/s?_biz=MjM5MjA0NjE1OQ==\&mid=2652036586\&idx $=2 \& \mathrm{sn}=4 \mathrm{c}$ 4c64310a3c844799918dcb85f5a4d3\&chksm=bd4a30ca8a3db9dcdc131b518a0a999461c15a8 371eb5ac6a6043db558c5393de36bcdbd7e5e \&mpshare=1\&scene=23\&srcid=0724ZyEWHQ 6E2s1P52COsGCC\&sharer_sharetime $=1595605482709 \&$ sharer_shareid=804c154d00cb9fad 2b6483d58bdd1e5b\#rd

Note 11. https://m.sohu.com/a/277319404_363248

Note 12. https://www.zhihu.com/question/303137080/answer/536699707

Note 13. http://mp.weixin.qq.com/s?_biz=MzI5NDYxNDc2NQ==\&mid=2247492194\&idx=1\&sn=1 c694a0668e775278f95531cf986776a\&chksm=ec6281e0db1508f65ba43d5708ce5729a68ed9 4d46043199922be9293d7f807b1005eb1 aa1 fa\&mpshare $=1 \&$ scene $=23 \&$ srcid $=0723 \mathrm{pW} 6 \mathrm{fmLj}$ 1qIZ4q0SF10LY\&sharer_sharetime $=1595519576611 \&$ sharer_shareid $=804 \mathrm{c} 154 \mathrm{~d} 00 \mathrm{cb} 9 \mathrm{fad} 2 \mathrm{~b}$ 6483d58bdd1e5b\#rd

Note 14. http://mp.weixin.qq.com/s?_biz=MzIzMTczOTY4Mw==\&mid=2247488675\&idx=1\&sn=0 1336ef1c221bbd48607ed57d69ec4f4\&chksm=e89eccefdfe 945f99818b4526d7177d1ba756f1 a808be77b6e85d6185c9b981 debb278cc3be8\&mpshare=1\&scene=23\&srcid=0724RDhOWL JLJW2wC02eShkv\&sharer_sharetime $=1595605733947 \&$ sharer_shareid=804c154d00cb9fad 2b6483d58bdd1e5b\#rd

Note 15. https://weibo.com/u/2019842447

Note 16. http://mp.weixin.qq.com/s?_biz=MzUxOTA4MDg3Mg==\&mid=2247483866\&idx=1\&sn= a25008ab5aa8d15b2866e9faef72e462\&chksm=f9fe5f1dce89d60b0f09774d65c7f7a3dae30d5 a0d93354e3cad0cc7ea968add56facef93062\&mpshare $=1 \&$ scene $=23 \&$ srcid= $=07234$ alvZE4tc5 gE8QTpxhIw\&sharer_sharetime $=1595519971926 \&$ sharer_shareid $=804 \mathrm{c} 154 \mathrm{~d} 00 \mathrm{cb} 9 \mathrm{fad} 2 \mathrm{~b} 648$ 3d58bdd1e 5b\#rd

Note 17. http://mp.weixin.qq.com/s?_biz=MzA5MjAwNzcwNQ==\&mid=2654433644\&idx=1\&sn=b 


\section{Macrothink}

International Journal of Linguistics

ISSN 1948-5425

2021, Vol. 13, No. 2

e6a999eb324d925c9ceca46856d9a52\&chksm=8bb06d1abcc7e40cbc68fbd7061cc346e 505a4 96e2eafe 712e 2e1034e5422c73fd74b35faace $\&$ mpshare $=1 \&$ scene $=23 \&$ srcid $=0805 \mathrm{WoVWcU}$ FYkNrbYOGPt0wP\&sharer_sharetime $=1596639736151 \&$ sharer_shareid $=804 \mathrm{c} 154 \mathrm{~d} 00 \mathrm{cb} 9 \mathrm{fa}$ d2b6483d58bdd1e5b\#rd

Note 18. https://zhuanlan.zhihu.com/p/50721247

Note 19. https://weibo.com/u/2019842447

Note

20.

http://mp.weixin.qq.com/s?_biz=MzA4MDgzMTEzMw==\&mid=2649499776\&idx=2\&sn= dca9c5685ea6facfe1cb1880774636c5\&chksm=8786bf72b0f13664953f1a0a3bd432b86fe38f2 6df7df17f9d252bbdc4bcf9e8b7932f2aff78\&mpshare $=1 \&$ scene $=23 \&$ srcid=07231DaLnD4PiF ptbOgDnmO6\&sharer_sharetime $=1595519920074 \&$ sharer_shareid $=804 \mathrm{c} 154 \mathrm{~d} 00 \mathrm{cb} 9 \mathrm{fad} 2 \mathrm{~b} 64$ 83d58bdd1e5b\#rd

Note 21. https://zhuanlan.zhihu.com/p/51568205

Note 22. https://www.zhihu.com/question/303370739/answer/537426795

Note 23.

http://mp.weixin.qq.com/s?_biz=MzI2OTk3NDgzNg==\&mid=2247484059\&idx=1\&sn=e3 132564f1287224f4d14f45d99643c8\&chksm=ead96ec0ddaee7d63f71f5c4daa09f9658faa68b8 c009b6e36c22bdb3ab2b53bd2711 c162abc\&mpshare=1\&scene=23\&srcid=0723 mf1Jt9YFeQ sV4RE7YOCT\&sharer_sharetime $=1595519699846 \&$ sharer_shareid $=804 \mathrm{c} 154 \mathrm{~d} 00 \mathrm{cb} 9 \mathrm{fad} 2 \mathrm{~b} 6$ 483d58bdd1e5b\#rd

Note 24. http://mp.weixin.qq.com/s?_biz=MzI1MTM2MTIzNw==\&mid=2247485679\&idx=1\&sn=1 c057ebccc79e1c44414d82891dc4142\&chksm=e9f56a55de82e343b894762b18386b0bae8d1f 517524fdbff93417c331e28793c8ee02a91fb7\&mpshare $=1 \&$ scene $=23 \&$ srcid $=0723$ YdrjGX7le OPOCATILmEP\&sharer_sharetime $=1595519368437 \&$ sharer_shareid $=804 \mathrm{c} 154 \mathrm{~d} 00 \mathrm{cb} 9 \mathrm{fad} 2 \mathrm{~b}$ 6483d58bdd1e5b\#rd

\section{Copyrights}

Copyright for this article is retained by the author(s), with first publication rights granted to the journal.

This is an open-access article distributed under the terms and conditions of the Creative Commons Attribution license (http://creativecommons.org/licenses/by/4.0/) 